\title{
Original
}

\section{The relationship between thyroid stimulating hormone within the reference range and coronary artery disease: impact of age}

\author{
Libo Yang ${ }^{1), 3)}$, Jianwen Zou ${ }^{2)}$, Mingliang Zhang ${ }^{4)}$, Hong Xu ${ }^{4)}$, Wenbo $\mathrm{Qi}^{3)}$, Ling Gao ${ }^{5)}$ and Jiajun Zhao ${ }^{1)}$ \\ 1) Department of Endocrinology, Provincial Hospital affiliated to Shandong University, Jinan, People's Republic of China \\ 2) Department of Clinical Laboratory, Provincial Hospital affiliated to Shandong University, Jinan, People's Republic of China \\ 3) Department of Endocrinology, Taian city Central Hospital, Taian, People's Republic of China \\ 4) Department of Cardiology, Taian city Central Hospital, Taian, People's Republic of China \\ 5) Department of Central Laboratory, Provincial Hospital affiliated to Shandong University, Jinan, People's Republic of China
}

\begin{abstract}
Studies on the relationship between thyroid stimulating hormone (TSH) within the reference range and coronary artery disease (CAD) have produced conflicting results. Furthermore, the effect of age on this relationship has never been explored. The aim of this study was to investigate the association between TSH levels and CAD among euthyroid subjects and whether age influenced this relationship. A total of 318 subjects who underwent coronary angiography were included. Serum TSH, T3, T4, lipid, blood glucose and creatinine levels were measured and compared between the groups with and without CAD. Age-stratified analysis and multivariate logistic regression analysis were performed. Levels of TSH, T3 and T4 did not differ significantly between CAD $(\mathrm{n}=196)$ and non-CAD group $(\mathrm{n}=122)(\mathrm{TSH}: 1.77 \pm 0.99 v s 1.89 \pm 0.98 \mathrm{mIU} / \mathrm{L}$, T3: $1.45 \pm 0.36$ vs $1.51 \pm 0.35 \mathrm{nmol} / \mathrm{L}$, T4: $100.06 \pm 20.49$ vs $103.95 \pm 24.06 \mathrm{nmol} / \mathrm{L}$, respectively) when comparisons were performed among all subjects. A significant between-group difference in levels of TSH was observed among subjects less than or equal to 65 years old (CAD group: $n=121$, non-CAD group: $n=106$ ), with higher TSH levels in CAD group $(2.03 \pm 0.94$ vs $1.75 \pm 0.97 \mathrm{mIU} / \mathrm{L}$, adjusted $p=0.024)$. Multivariate logistic regression analysis revealed that elevated level of TSH was an independent predictor for CAD (odds ratio: 1.512, $p=0.011$ ). No significant between-group difference in TSH levels was observed among subjects older than 65 years (CAD group: $n=75$, non-CAD group: $n=16$ ). The results showed that higher levels of TSH within the reference range were independently associated with the presence of CAD only among subjects less than or equal to 65 years old, suggesting age might influence the relationship.
\end{abstract}

Key words: Thyrotropin, Coronary artery disease, Age Factors

OVERT HYPOTHYROIDISM is known to predispose patients to cardiovascular diseases [1]. However, controversies exist regarding whether subclinical hypothyroidism ( $\mathrm{SCH})$, defined as a serum thyroid stimulating hormone (TSH) concentration above the normal range with normal serum free $\mathrm{T} 4$ and free $\mathrm{T} 3$ concentration, is associated with coronary artery disease (CAD) and its mortality. Some [2-5] but not all studies [6-8] showed a positive association between them. Recently, these associations have been further investigated among individuals with normal thyroid function.

Submitted Dec. 10, 2012; Accepted Jan. 29, 2013 as EJ12-0448 Released online in J-STAGE as advance publication Mar. 8, 2013

Correspondence to: Jiajun Zhao, Department of Endocrinology, Provincial Hospital affiliated to Shandong University, 324 Jing 5 Road, Jinan 250021, People's Republic of China.

E-mail: jjzhao@medmail.com.cn
One prospective study indicated TSH levels within the reference range were positively and linearly associated with cardiovascular mortality in women [9] and four cross-sectional studies [10-13] reported that relatively low thyroid function within the reference range was associated with the presence of CAD, while two others [14-15] did not confirm these findings. These results arouse the debate on whether there is a need to redefine the upper normal limit of TSH [16-17].

It has been reported that age influences the relationship between SCH and CAD [18], with increased risks for CAD in younger but not older individuals. However, few studies have explored the role of age in the link between thyroid function and CAD in euthyroid subjects so far. To address this issue, we conducted this study to investigate the relationship between TSH within the reference range and CAD and the modifica- 
tion effect of age.

\section{Methods}

\section{Subjects}

Patients who underwent coronary angiography because of chest pain during the period from January 2012 to October 2012 were retrospectively reviewed. The exclusion criteria were as follows: (1) Abnormal serum levels of TSH, T4 or T3; (2) History of thyroid dysfunction or under treatment with thyroid medication; (3) Acute or past myocardial infarction; (4) History of revascularization of coronary artery; (5) severe cardiac, hepatic or renal dysfunction; (6) Medication with amiodarone, sex hormones and steroid hormones. Finally, a total of 318 subjects were included. The project was approved by the local Ethics Committee.

\section{Data collection}

Information of past medications and risk factors for CAD, including smoking, hypertension and diabetes were obtained from medical records. The body mass index (BMI) was calculated by dividing the weight $(\mathrm{Kg})$ with the square of height $\left(\mathrm{m}^{2}\right)$. Coronary angiography was carried out via the radial artery or femoral artery. Coronary angiographic findings were reviewed by two expert cardiologists and significant stenosis was defined as a diameter stenosis of $50 \%$ or greater.

Before angiography, fasting venous blood specimens were collected to measure lipid profile, blood glucose, creatinine and thyroid hormones. The lipid profile, blood glucose and creatinine were measured by an automatic biochemistry analyzer (Modular DPP, Roche, Switzerland) and commercial kits. The levels of T3, T4 and TSH were measured by using a chemiluminescence immunoassay (ADVIA Centaur XP, Siemens, USA). The laboratory reference ranges for TSH, T3, and T4 were $0.3-5.0 \mathrm{mIU} / \mathrm{L}, 0.92-2.79 \mathrm{nmol} / \mathrm{L}$, and 24.5-171.6 nmol/L, respectively.

\section{Statistical analysis}

Data were represented as mean \pm standard deviation. Inter-group analysis was done by using independent $t$ test, Mann-Whitney $\mathrm{U}$ test and chi-square test. Analysis of covariance was performed to adjust for age and sex. Multivariate logistic regression analysis was done to determine risk factors relating to CAD. Statistical significance was set at $p<0.05$. All the above analyses were conducted with the use of SPSS software
(SPSS Inc., Chicago, IL, USA) in version 17.0.

\section{Results}

\section{All subject analysis}

A total of $38.4 \%$ of the patients did not have CAD, whereas $31.4 \%$ and $30.2 \%$ presented single-vessel and multivessel CAD, respectively. Levels of TSH, T3 and T4 were similar between CAD and non-CAD group (TSH: $1.77 \pm 0.99$ vs $1.89 \pm 0.98 \mathrm{mIU} / \mathrm{L}, \mathrm{T} 3: 1.45 \pm 0.36 v s$ $1.51 \pm 0.35 \mathrm{nmol} / \mathrm{L}, \mathrm{T} 4: 100.06 \pm 20.49$ vs $103.95 \pm 24.06$ $\mathrm{nmol} / \mathrm{L}$, respectively). TSH levels between the group with single-vessel CAD and multivessel CAD also did not differ significantly $(2.00 \pm 0.99$ vs $1.77 \pm 0.96 \mathrm{mIU} / \mathrm{L}$, $p=0.096$ ). Age and percentage of male, diabetes, smoking and hypertension were significantly higher in CAD group compared with non-CAD group, while levels of high-density lipoprotein cholesterol (HDL-c) were relatively lower in CAD group. No significant differences on BMI, total cholesterol (TC), triglyceride (TG), lowdensity lipoprotein cholesterol (LDL-c) and creatinine between the two groups were found. After adjusting for both age and sex, the above results did not change significantly except TG. The characteristics of the total subjects and comparisons were displayed in Table 1.

\section{Age-stratified analysis}

When analysis was restricted to participants less than or equal to 65 years old, levels of TSH were significantly higher in CAD group than in non-CAD group $(2.03 \pm 0.94$ vs $1.75 \pm 0.97 \mathrm{mIU} / \mathrm{L}$, adjusted $p=0.024)$. Levels of T3 and $\mathrm{T} 4 \mathrm{did}$ not differ between two groups. No significant difference in TSH levels was observed between patients with single vessel CAD and multivessel CAD ( $2.13 \pm 0.93$ vs $1.89 \pm 0.95 \mathrm{mIU} / \mathrm{L}, p=0.158)$. Besides, significant between-group differences were observed with respect to age, HDL-c and percentage of smokers, hypertension and diabetes. Adjustment for age and sex did not significantly change the above results (Table 2).

To further assess the relationship between TSH and CAD among subjects less than or equal to 65 years old of age, these patients were divided into two categories based on the median value of TSH : G1 (TSH: 0.3-1.72 $\mathrm{mIU} / \mathrm{L}$ ) and G2 (TSH: 1.73-4.64 mIU/L). As shown in the Fig. 1, there were significantly more patients with CAD in G2 group as compared with G1 group (61.9\% vs $44.7 \%, p=0.009$ ). Multiple logistic regression analysis showed elevated TSH level was an independent risk factor for $\mathrm{CAD}$, with an adjusted odds ratio (OR) 
Table 1 Clinical characteristics of total subjects

\begin{tabular}{|c|c|c|c|c|c|}
\hline Variables & Overall $(n=318)$ & Non-CAD $(n=122)$ & CAD $(n=196)$ & $p$ value & $p^{\prime}$ value \\
\hline Age (years) & $59.42 \pm 10.60$ & $54.81 \pm 10.17$ & $62.29 \pm 9.87$ & 0.000 & \\
\hline Male (\%) & 59.1 & 51.6 & 63.8 & 0.032 & \\
\hline BMI $\left(\mathrm{kg} / \mathrm{m}^{2}\right)$ & $24.82 \pm 3.23$ & $24.71 \pm 3.27$ & $24.89 \pm 3.21$ & 0.641 & 0.105 \\
\hline Smoker (\%) & 35.5 & 26.2 & 41.3 & 0.006 & 0.028 \\
\hline Hypertension (\%) & 61.3 & 50 & 68.4 & 0.001 & 0.005 \\
\hline Diabetes $(\%)$ & 18.6 & 11.5 & 23.0 & 0.010 & 0.007 \\
\hline $\mathrm{FBG}(\mathrm{mmol} / \mathrm{L})$ & $5.83 \pm 1.59$ & $5.68 \pm 1.58$ & $5.93 \pm 1.59$ & 0.152 & 0.153 \\
\hline $\mathrm{TC}(\mathrm{mmol} / \mathrm{L})$ & $4.67 \pm 1.17$ & $4.79 \pm 1.01$ & $4.64 \pm 1.02$ & $0.256^{\mathrm{a}}$ & $0.642^{\mathrm{a}}$ \\
\hline LDL-c $(\mathrm{mmol} / \mathrm{L})$ & $2.73 \pm 0.82$ & $2.84 \pm 0.82$ & $2.74 \pm 0.83$ & $0.379^{\mathrm{a}}$ & $0.523^{\mathrm{a}}$ \\
\hline $\mathrm{TG}(\mathrm{mmol} / \mathrm{L})$ & $1.67 \pm 1.77$ & $1.50 \pm 0.74$ & $1.60 \pm 1.31$ & $0.096^{\mathrm{a}}$ & $0.035^{\mathrm{a}}$ \\
\hline HDL-c (mmol/L) & $1.27 \pm 0.34$ & $1.37 \pm 0.40$ & $1.24 \pm 0.28$ & $0.005^{\mathrm{a}}$ & $0.017^{\mathrm{a}}$ \\
\hline Creatinine $(\mu \mathrm{mol} / \mathrm{L})$ & $66.31 \pm 13.12$ & $64.99 \pm 14.17$ & $67.12 \pm 12.39$ & 0.181 & 0.962 \\
\hline $\mathrm{TSH}(\mathrm{mIU} / \mathrm{L})$ & $1.84 \pm 0.98$ & $1.77 \pm 0.99$ & $1.89 \pm 0.98$ & 0.227 & 0.063 \\
\hline T3 (nmol/L) & $1.49 \pm 0.36$ & $1.45 \pm 0.36$ & $1.51 \pm 0.35$ & 0.135 & 0.371 \\
\hline $\mathrm{T} 4(\mathrm{nmol} / \mathrm{L})$ & $102.45 \pm 22.80$ & $100.06 \pm 20.49$ & $103.95 \pm 24.06$ & 0.147 & 0.233 \\
\hline
\end{tabular}

BMI, body mass index; FBG, fasting blood glucose; TC, total cholesterol; TG, triglyceride; LDL-c, low density lipoproteincholesterol; HDL-c, high density lipoprotein-cholesterol; TSH, thyroid stimulating hormone; $p$ value, unadjusted; $p$ ' value, adjusted for age and sex; ${ }^{\text {a }}$, Comparisons were made after excluding 67 subjects who were on statin therapy

Table 2 Clinical characteristics of subjects less than or equal to 65 years old

\begin{tabular}{lcccc}
\hline Variables & Non-CAD $(\mathrm{n}=106)$ & $\mathrm{CAD}(\mathrm{n}=121)$ & $p$ value & $p^{\prime}$ value \\
\hline Age $($ years $)$ & $52.44 \pm 8.62$ & $56.20 \pm 7.00$ & 0.000 & \\
Male $(\%)$ & 53.8 & 63.6 & 0.132 & \\
BMI $\left(\mathrm{kg} / \mathrm{m}^{2}\right)$ & $24.75 \pm 3.38$ & $25.41 \pm 3.25$ & 0.138 & 0.053 \\
Smoker $(\%)$ & 28.3 & 43.8 & 0.016 & 0.054 \\
Hypertension $(\%)$ & 48.1 & 66.9 & 0.004 & 0.006 \\
Diabetes $(\%)$ & 12.3 & 22.3 & 0.047 & 0.028 \\
FBG $(\mathrm{mmol} / \mathrm{L})$ & $5.73 \pm 1.72$ & $6.01 \pm 1.72$ & 0.225 & 0.328 \\
TC $(\mathrm{mmol} / \mathrm{L})$ & $4.82 \pm 1.05$ & $4.59 \pm 1.02$ & $0.116^{\mathrm{a}}$ & $0.250^{\mathrm{a}}$ \\
LDL-c $(\mathrm{mmol} / \mathrm{L})$ & $2.85 \pm 0.86$ & $2.71 \pm 0.82$ & $0.253^{\mathrm{a}}$ & $0.319^{\mathrm{a}}$ \\
TG $(\mathrm{mmol} / \mathrm{L})$ & $1.53 \pm 0.77$ & $1.70 \pm 1.50$ & $0.346^{\mathrm{a}}$ & $0.061^{\mathrm{a}}$ \\
HDL-c $(\mathrm{mmol} / \mathrm{L})$ & $1.39 \pm 0.41$ & $1.21 \pm 0.28$ & $0.002^{\mathrm{a}}$ & $0.001^{\mathrm{a}}$ \\
Creatinine $(\mu \mathrm{mol} / \mathrm{L})$ & $64.87 \pm 14.22$ & $66.61 \pm 11.89$ & 0.317 & 0.926 \\
TSH $(\mathrm{mIU} / \mathrm{L})$ & $1.75 \pm 0.97$ & $2.03 \pm 0.94$ & 0.028 & 0.024 \\
T3 $(\mathrm{nmol} / \mathrm{L})$ & $1.46 \pm 0.35$ & $1.51 \pm 0.33$ & 0.309 & 0.818 \\
T4 $(\mathrm{nmol} / \mathrm{L})$ & $99.77 \pm 20.87$ & $104.02 \pm 24.84$ & 0.294 & 0.313 \\
\hline BMI Body & &
\end{tabular}

BMI, Body mass index; FBG, fasting blood glucose; TC, total cholesterol; TG, triglyceride; LDL-c, low density lipoprotein-cholesterol; HDL-c, high density lipoprotein-cholesterol; TSH, thyroid stimulating hormone; $p$ value, unadjusted; $p$ ' value, adjusted for age and sex; ${ }^{\text {a }}$, Comparisons were made after excluding 39 subjects who were on statin therapy

of 1.512 (95\% CI: $1.100-2.078, p=0.011)$. Other significant risk factors for predicting $\mathrm{CAD}$ were age (OR: 1.080, 95\% CI: 1.038-1.124, $p=0.000)$, hypertension (OR: $1.883,95 \%$ CI: $1.033-3.432, p=0.039$ ) and HDL-c (OR: 0.243, 95\% CI: 0.087-0.681, $p=0.007$ ) (Table 3).

Among subjects older than 65 years, no significant differences in TSH, T3 and T4 between CAD group and non-CAD group were observed (TSH: $1.66 \pm 1.0 v \mathrm{~s}$ $1.89 \pm 1.09 \mathrm{mIU} / \mathrm{L}$, adjusted $p=0.772$; T3: $1.52 \pm 0.39 v s$
$1.35 \pm 0.36 \mathrm{nmol} / \mathrm{L}$, adjusted $p=0.145 ; \mathrm{T} 4: 103.83 \pm 22.89$ vs $101.96 \pm 18.32 \mathrm{nmol} / \mathrm{L}$, adjusted $p=0.524$; respectively). The comparisons of other variables were shown in Table 4. When the median value of TSH was used as a cut-off to divide the subjects into two groups, the percentage of CAD was similar between the two groups $(82.6 \%$ vs $82.2 \%, p=0.961)$. The results of multiple logistic regression analysis were showed in Table 5. The results should be interpreted with caution, espe- 


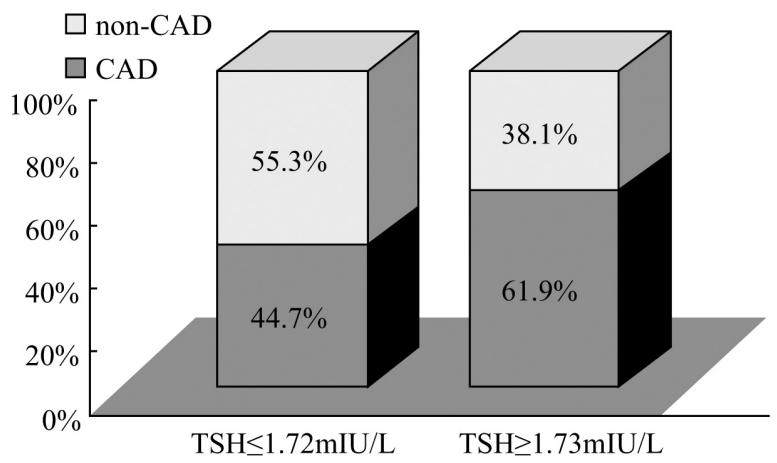

Fig. 1 The frequency (\%) of coronary artery disease according to the categories of TSH among subjects less than or equal to 65 years old
Table 3 Multivariate logistic regression analysis for coronary artery disease among subjects less than or equal to 65 years old

\begin{tabular}{lccc}
\hline Variables & Odds ratio & $95 \%$ CI & $p$ value \\
\hline Age & 1.080 & $1.038-1.124$ & 0.000 \\
Smoking & 1.845 & $0.895-3.800$ & 0.097 \\
Hypertension & 1.883 & $1.033-3.432$ & 0.039 \\
HDL-c & 0.243 & $0.087-0.681$ & 0.007 \\
TSH & 1.512 & $1.100-2.078$ & 0.011 \\
Sex & 1.212 & $0.588-2.499$ & 0.602 \\
Diabetes & 1.664 & $0.751-3.689$ & 0.210 \\
\hline
\end{tabular}

HDL-c, high density lipoprotein-cholesterol

Table 4 Clinical characteristics of subjects older than 65 years

\begin{tabular}{lcccc}
\hline Variables & Non-CAD $(\mathrm{n}=16)$ & CAD $(\mathrm{n}=75)$ & $p$ value & $p^{\prime}$ value \\
\hline Age (years) & $70.50 \pm 3.46$ & $72.13 \pm 4.32$ & 0.160 & \\
Male $(\%)$ & 37.5 & 64.0 & 0.050 & \\
BMI $\left(\mathrm{kg} / \mathrm{m}^{2}\right)$ & $24.44 \pm 2.52$ & $24.04 \pm 2.97$ & 0.625 & 0.719 \\
Smoker $(\%)$ & 12.5 & 37.3 & 0.055 & 0.241 \\
Hypertension (\%) & 62.5 & 70.7 & 0.558 & 0.370 \\
Diabetes (\%) & 6.3 & 24.0 & 0.176 & 0.139 \\
FBG (mmol/L) & $5.56 \pm 0.36$ & $5.80 \pm 1.36$ & 0.521 & 0.357 \\
TC $(\mathrm{mmol} / \mathrm{L})$ & $4.45 \pm 0.51$ & $4.73 \pm 1.05$ & $0.413^{\mathrm{a}}$ & $0.091^{\mathrm{a}}$ \\
LDL-c (mmol/L) & $2.73 \pm 0.47$ & $2.81 \pm 0.85$ & $0.793^{\mathrm{a}}$ & $0.422^{\mathrm{a}}$ \\
TG (mmol/L) & $1.27 \pm 0.35$ & $1.41 \pm 0.85$ & $0.829^{\mathrm{a}}$ & $0.307^{\mathrm{a}}$ \\
HDL-c (mmol/L) & $1.19 \pm 0.24$ & $1.32 \pm 0.29$ & $0.194^{\mathrm{a}}$ & $0.032^{\mathrm{a}}$ \\
Creatinine (umol/L) & $65.50 \pm 13.80$ & $67.95 \pm 13.21$ & 0.506 & 0.773 \\
TSH (mIU/L) & $1.89 \pm 1.09$ & $1.66 \pm 1.0$ & 0.423 & 0.772 \\
T3 (nmol/L) & $1.35 \pm 0.36$ & $1.52 \pm 0.39$ & 0.130 & 0.145 \\
T4 (nmol/L) & $101.96 \pm 18.32$ & $103.83 \pm 22.89$ & 0.761 & 0.524 \\
\hline BMI Body mass & & & & \\
\hline
\end{tabular}

BMI, Body mass index; FBG, fasting blood glucose; TC, total cholesterol; TG, triglyceride; LDL-c, low density lipoprotein-cholesterol; HDL-c, high density lipoprotein-cholesterol; TSH, thyroid stimulating hormone; $p$ value, unadjusted; $p$ ' value, adjusted for age and sex; ${ }^{\text {a }}$, Comparisons were made after excluding 29 subjects who were on statin therapy

Table 5 Multivariate logistic regression analysis for coronary artery disease among subjects older than 65 years

\begin{tabular}{lccc}
\hline Variables & Odds ratio & $95 \% \mathrm{CI}$ & $p$ value \\
\hline Age & 1.168 & $0.978-1.396$ & 0.087 \\
Smoking & 2.497 & $0.405-15.381$ & 0.324 \\
Hypertension & 2.382 & $0.601-9.448$ & 0.217 \\
HDL-c & 24.084 & $1.559-371.959$ & 0.023 \\
TSH & 1.099 & $0.589-2.049$ & 0.767 \\
Sex & 0.203 & $0.041-1.002$ & 0.050 \\
Diabetes & 7.646 & $0.828-70.643$ & 0.073 \\
\hline
\end{tabular}

HDL-c, high density lipoprotein-cholesterol 
cially for HDL-c, which was positively associated with $\mathrm{CAD}$ and its $95 \%$ confidence interval was very wide. This might be partly due to small number of non-CAD subjects older than 65 years $(n=16)$.

\section{Discussion}

Studies on the relationship between normal range of thyroid function and $\mathrm{CAD}$ had produced inconsistent results [10-15]. The discrepancies might derive from the number of enrollment, heterogenous subjects and racial difference et al. However, the effect of age on this relationship was neglected and none of them performed an age-stratified analysis. In the present study, a significant and independent association between elevated TSH levels within the reference range and CAD was observed in younger individuals but not in all or older individuals. This finding suggested that age might play a role in the relationship of TSH and CAD.

The impact of age on the CAD risks in people with $\mathrm{SCH}$ has been investigated by some studies. It has been reported that in elderly individuals (at least 65 year old or older) high levels of TSH were not associated with an increased risk of CAD and its mortality [19-21]. Furthermore, in the study by Gussekloo $\mathrm{J}$ et al. [22], which included 599 subjects who were aged 85 years at enrollment and followed for a mean period of 3.7 years, individuals with higher TSH levels had a longer life span than controls, suggesting a protective effect of $\mathrm{SCH}$ in elderly individuals. Two meta-analyses showed that the association between $\mathrm{SCH}$ and CAD was stronger [23] or only existed [18] among individuals younger than 65 years old. A recent large intervention study lasting for a median period of 7.6 years indicated that treatment of SCH with levothyroxine resulted in a significant reduction of ischemia heart diseases events in younger individuals, but not in older people [24]. These results, along with ours, further supported that higher levels of TSH may have different effects for younger and older population, with more adverse effects on the former. The underlying mechanisms remained unknown. Different Thyroid physiology in older and younger had been documented, with a decreased thyroid hormone metabolism [25] and increased TSH levels $[20,26]$ in the elderly. This agerelated change of thyroid function may be one of the mechanisms explaining the effect of age on CAD risks. Other possible explanations included different effects of increased TSH on vascular risks during aging and more conventional risk factors in the older to mask the adverse effects of higher TSH levels.

The exact underlying mechanisms involved in the association between high TSH levels with the reference range and $\mathrm{CAD}$ remain uncertain. Our previous studies showed that TSH levels were positively associated with hypercholesterolemia independent of thyroid hormones among euthyroid subjects [27]. Other studies reported high levels of TSH with the reference range were associated with hypertension [28], impaired endothelial function [29], arterial stiffness [30] ,metabolic syndrome [31] and renal dysfunction [32]. These findings may partly explain why individuals with TSH levels in the upper part of the reference range are at high risk for CAD.

Some potential limitations should be addressed. Fist, a causal relationship cannot be established from this cross-sectional study. Second, we did not measure serum free T3 and free T4 levels, which were active forms of thyroid hormones. However, the aim of our study was to assess the relationship of TSH and CAD in euthyroid subjects and simultaneous measurements of TSH, total T3 and total T4 were enough to establish a euthyroid state. Third, because this was a retrospective and hospital-based study, selection bias existed. Four, the number of subjects in the elderly subgroup was relatively small, which may influence the statistic power of sub-analysis. Five, single measurement of thyroid hormones may result in misclassification since thyroid function is influenced by nonthyroidal illnesses [33]. However, because stringent exclusion criteria were used in this study, such potential confounding was minimized.

In conclusion, this study showed that high levels of TSH within the reference range were independently associated with the presence of CAD only among subjects less than or equal to 65 years old of age, suggesting a modification effect of age on this relationship. Correlation between levels of TSH and severity of CAD was not observed. Well-designed prospective studies should be necessary to fully clarify the relationship of high levels of TSH with the presence and severity of CAD and the role of age.

\section{Conflict of Interest}

The authors declare no conflicts of interest. 


\section{Fund Support}

This work was supported by grants from the National Basic Research Program (2012CB524900), the National Natural Science Foundation (30971409, 81230018, 81170794 and 81270869), the Natural
Science Foundation (2012GSF11824, ZR2009CZ009), an international cooperation grant (2011) of Shandong Province, and the Jinan self-renovation plan for colleges, universities and scientific research institutes (2012) of China.

\section{References}

1. Cappola AR, Ladenson PW (2003) Hypothyroidism and atherosclerosis. J Clin Endocrinol Metab 88: 24382444.

2. Imaizumi M, Akahoshi M, Ichimaru S, Nakashima E, Hida A, et al. (2004) Risk for ischemic heart disease and all-cause mortality in subclinical hypothyroidism. $J$ Clin Endocrinol Metab 89: 3365-3370.

3. Walsh JP, Bremner AP, Bulsara MK, O'Leary P, Leedman PJ, et al. (2005) Subclinical thyroid dysfunction as a risk factor for cardiovascular disease. Arch Intern Med 165: 2467-2472.

4. Tseng FY, Lin WY, Lin CC, Lee LT, Li TC, et al. (2012) Subclinical hypothyroidism is associated with increased risk for all-cause and cardiovascular mortality in adults. J Am Coll Cardiol 60: 730-737.

5. Iervasi G, Molinaro S, Landi P, Taddei MC, Galli E, et al. (2007) Association between increased mortality and mild thyroid dysfunction in cardiac patients. Arch Intern Med 167: 1526-1532.

6. Cappola AR, Fried LP, Arnold AM, Danese MD, Kuller LH, et al. (2006) Thyroid status, cardiovascular risk, and mortality in older adults. JAMA 295: 1033-1041.

7. Rodondi N, Newman AB, Vittinghoff E, de Rekeneire N, Satterfield S, et al. (2005) Subclinical hypothyroidism and the risk of heart failure, other cardiovascular events, and death. Arch Intern Med 165: 2460-2466.

8. Boekholdt SM, Titan SM, Wiersinga WM, Chatterjee $\mathrm{K}$, Basart DC, et al. (2010) Initial thyroid status and cardiovascular risk factors: the EPIC-Norfolk prospective population study. Clin Endocrinol (Oxf) 72: 404-410.

9. Asvold BO, Bjoro T, Nilsen TI, Gunnell D, Vatten LJ (2008) Thyrotropin levels and risk of fatal coronary heart disease: the HUNT study. Arch Intern Med 168: 855-860.

10. Miura S, Iitaka M, Suzuki S, Fukasawa N, Kitahama S, et al. (1996) Decrease in serum levels of thyroid hormone in patients with coronary heart disease. Endocr $J$ 43: 657-663.

11. Yun KH, Jeong MH, Oh SK, Lee EM, Lee J, et al. (2007) Relationship of thyroid stimulating hormone with coronary atherosclerosis in angina patients. Int $J$ Cardiol 122: 56-60.

12. Coceani M, Iervasi G, Pingitore A, Carpeggiani C, L'Abbate A (2009) Thyroid hormone and coronary artery disease: from clinical correlations to prognostic implications. Clin Cardiol 32: 380-385.

13. Auer J, Berent R, Weber T, Lassnig E, Eber B (2003) Thyroid function is associated with presence and severity of coronary atherosclerosis. Clin Cardiol 26: 569573.

14. Peters A, Ehlers M, Blank B, Exler D, Falk C, et al. (2000) Excess triiodothyronine as a risk factor of coronary events. Arch Intern Med 160: 1993-1999.

15. Jung $\mathrm{CH}$, Rhee EJ, Shin HS, Jo SK, Won JC, et al. (2008) Higher serum free thyroxine levels are associated with coronary artery disease. Endocr J 55: 819826.

16. Brabant G, Beck-Peccoz P, Jarzab B, Laurberg P, Orgiazzi J, et al. (2006) Is there a need to redefine the upper normal limit of TSH? Eur J Endocrinol 154: 633637.

17. Waise A, Price HC (2009) The upper limit of the reference range for thyroid-stimulating hormone should not be confused with a cut-off to define subclinical hypothyroidism. Ann Clin Biochem 46: 93-98.

18. Razvi S, Shakoor A, Vanderpump M, Weaver JU, Pearce SH (2008) The influence of age on the relationship between subclinical hypothyroidism and ischemic heart disease: a metaanalysis. J Clin Endocrinol Metab 93: 2998-3007.

19. Hyland KA, Arnold AM, Lee JS, Cappola AR (2013) Persistent Subclinical Hypothyroidism and Cardiovascular Risk in the Elderly: The Cardiovascular Health Study. J Clin Endocrinol Metab 98: 533-540.

20. Waring AC, Arnold AM, Newman AB, Buzkova P, Hirsch C, Cappola AR (2012) Longitudinal changes in thyroid function in the oldest old and survival: the cardiovascular health study all-stars study. J Clin Endocrinol Metab 97: 3944-3950.

21. Waring AC, Harrison S, Samuels MH, Ensrud KE, Le BES, et al. (2012) Thyroid function and mortality in older men: a prospective study. J Clin Endocrinol Metab 97: 862-870.

22. Gussekloo J, van Exel E, de Craen AJ, Meinders AE, Frolich M, Westendorp RG (2004) Thyroid status, disability and cognitive function, and survival in old age. JAMA 292: 2591-2599.

23. Ochs N, Auer R, Bauer DC, Nanchen D, Gussekloo J, et 
al. (2008) Meta-analysis: subclinical thyroid dysfunction and the risk for coronary heart disease and mortality. Ann Intern Med 148: 832-845.

24. Razvi S, Weaver JU, Butler TJ, Pearce SH (2012) Levothyroxine Treatment of Subclinical Hypothyroidism, Fatal and Nonfatal Cardiovascular Events, and Mortality. Arch Intern Med 172: 811-817.

25. Mariotti S, Franceschi C, Cossarizza A, Pinchera A (1995) The aging thyroid. Endocr Rev 16: 686-715.

26. Bremner AP, Feddema P, Leedman PJ, Brown SJ, Beilby JP, et al. (2012) Age-related changes in thyroid function: a longitudinal study of a community-based cohort. J Clin Endocrinol Metab 97: 1554-1562.

27. Wang F, Tan Y, Wang C, Zhang X, Zhao Y, et al. (2012) Thyroid-stimulating hormone levels within the reference range are associated with serum lipid profiles independent of thyroid hormones. J Clin Endocrinol Metab 97: 2724-2731.

28. Ittermann T, Thamm M, Wallaschofski H, Rettig R, Volzke H (2012) Serum thyroid-stimulating hormone levels are associated with blood pressure in children and adolescents. J Clin Endocrinol Metab 97: 828-834.

29. Volzke H, Robinson DM, Spielhagen T, Nauck M, Obst A, et al. (2009) Are serum thyrotropin levels within the reference range associated with endothelial function? Eur Heart J 30: 217-224.

30. Lambrinoudaki I, Armeni E, Rizos D, Georgiopoulos G, Kazani M, et al. (2012) High normal thyroid-stimulating hormone is associated with arterial stiffness in healthy postmenopausal women. J Hypertens 30: 592-599.

31. Ruhla S, Weickert MO, Arafat AM, Osterhoff M, Isken F, et al. (2010) A high normal TSH is associated with the metabolic syndrome. Clin Endocrinol (Oxf) 72: 696-701.

32. Sun MT, Hsiao FC, Su SC, Pei D, Hung YJ (2012) Thyrotropin as an independent factor of renal function and chronic kidney disease in normoglycemic euthyroid adults. Endocr Res 37: 110-116.

33. Papanicolaou DA (2000) Euthyroid Sick Syndrome and the role of cytokines. Rev Endocr Metab Disord 1: 43-48. 